\title{
miR-378 in combination with ultrasonic irradiation and SonoVue microbubbles transfection inhibits hepatoma cell growth
}

\author{
JIANJUN WANG $^{1 *}$, YUNCHUN LI $^{2 *}$, QIANFENG MA ${ }^{1}$ and JIAXIN HUANG ${ }^{3}$ \\ ${ }^{1}$ Department of Ultrasonography, General Hospital of Ningxia Medical University, Yinchuan, Ningxia Hui Autonomous \\ Region 750004; ${ }^{2}$ Laboratory Center, Jinshan Hospital of Fudan University, Shanghai 201508; \\ ${ }^{3}$ Li Ka Shing Faculty of Medicine, The University of Hong Kong, Hong Kong 999077, SAR, P.R. China
}

Received September 4, 2019; Accepted February 20, 2020

DOI: $10.3892 / \mathrm{mmr} .2020 .11045$

\begin{abstract}
Ultrasonic microbubbles in combination with microRNA (miRNAs/miRs) exhibited promising effects on cancer treatments. The aim was to investigate the role of miR-378 in hepatoma cells and the efficiency of it in combination with ultrasonic irradiation and SonoVue ${ }^{\circledR}$ microbubbles method for cell transfection. HuH-7, Hep3B and SK-Hep1 cells were transfected with an miR-378 mimic using only Lipofectamine ${ }^{\circledR} 3000$ or combined with SonoVue microbubbles and ultrasonic irradiation at $0.5 \mathrm{~W} / \mathrm{cm}^{2}$ for $30 \mathrm{sec}$. mRNAs and protein levels of Cyclin D1, Bcl-2, Bax, Akt, p53 and Survivin were detected by reverse transcription-quantitative PCR and western blotting, respectively. Cell survival rate, proliferation, cell cycle and apoptosis were determined by Cell Counting Kit-8, cell double cytochemical staining and flow cytometry, respectively. It was found that using a combination of ultrasonic irradiation and the SonoVue microbubbles method increased the effectiveness of miR-378 transfection into hepatocellular carcinoma (HCC) cells, and increased the inhibition of cell survival and proliferation. Moreover, miR-378 increased the rate of apoptosis and upregulated the expression of Bax and p53, and suppressed the cell cycle and downregulated the expression of Cyclin D1, Bcl-2, Akt, $\beta$-catenin and Survivin much more effectively in the HCC cell line by applying the combined method. Thus, miR-378 was shown to be a suppressive factor to reduce proliferation and increase apoptosis in HCC cells. Additionally, the combination of ultrasonic irradiation and SonoVue microbubbles method was more efficient in the transfection of miRNA.
\end{abstract}

Correspondence to: Professor Jianjun Wang, Department of Ultrasonography, General Hospital of Ningxia Medical University, 804 Shengli South Street, Xingqing, Yinchuan, Ningxia Hui Autonomous Region 750004, P.R. China

E-mail: wangjianjun_jw@163.com

*Contributed equally

Key words: miRNA, hepatoma, ultrasonic irradiation, microbubbles

\section{Introduction}

The pathogenesis of hepatocellular carcinoma (HCC) has not yet been fully clarified and there is still a lack of targeted therapies for HCC $(1,2)$. For patients with the disease, radical resection of $\mathrm{HCC}$ is the main treatment in its early stages, but $>50 \%$ of post-operative patients show metastasis and recurrence within 5 years $(1,2)$. Targeted drugs for HCC are emerging, providing possible new therapies to prevent and cure malignant cancer (3). However, its therapeutic effects are still not satisfactory, due to the side effects it has on normal cells (4). Thus, the current treatments for HCC still face several challenges.

Studies conducted to investigate HCC genes at molecular level indicate that a number of genes and proteins are closely related to the malignant characteristics of HCC staging, recurrence and metastasis, and these molecules may play important roles in the occurrence and development of $\operatorname{HCC}(5,6)$. Thousands of microRNAs (miRNAs/miRs) exist in the human genome and each miRNA can directly regulate 200 target genes, and nearly $33 \%$ of the protein-coding genes in humans are controlled by miRNAs (5-7). Therefore, miRNAs occupy an indispensable position in the spectrum of human gene, thus, studying gene therapy for the treatment of hepatoma from the aspect of miRNA regulation has great potential.

Continuous research and development of ultrasound molecular imaging and biomedical engineering, especially development of targeted contrast microbubbles carrying various drugs and genes, have laid a solid foundation for building up ultrasonic microbubble technology for therapeutic use (8-11). Ultrasonic microbubbles are microbubbles composed of a core gas surrounded by a shell membrane with the size of $2-8 \mu \mathrm{m}$ or even smaller (12). As lipids (represented by SonoVue ${ }^{\circledR}$ ) have higher efficiency, fewer side effects and high stability, it has become the most widely used microbubbles in most studies (12-15). The mechanism of ultrasound-mediated targeted delivery mainly relies on cavitation and sonication effects of ultrasonic microbubbles generated under the irradiation of ultrasonic field strength (16). Ultrasound-targeted microbubbles show various modifications in their shell membranes and they can carry a variety of drugs or genes and can bind to specific antigens or genes expressed by specific cells in the body, thus providing the possibility of ultrasound-mediated targeted treatment (17). 
Currently, the delivery of nucleic acid via microbubbles and ultrasound method has attracted much attention due to the discovery of the potentials of miRNAs in modulating target genes (18). In view of these valuable prospects, the present study aimed to investigate the role of miR-378 in hepatoma cells and the efficiency of combining ultrasonic irradiation and SonoVue microbubbles for cell transfection.

\section{Materials and methods}

Cell incubation. HuH-7 cell line was purchased from the Japanese Collection of Research Bioresources Cell Bank, while Hep3B cell line was purchased from American Type Culture Collection and SK-Hepl cell line was purchased from The Cell Bank of Type Culture Collection of the Chinese Academy of Sciences. All the cell lines were cultured in DMEM (D0819; Sigma-Aldrich; Merck KGaA) containing 10\% FBS (F8192; Sigma-Aldrich; Merck KGaA) and penicillin-streptomycin reagent (V900929; Sigma-Aldrich; Merck $\mathrm{KGaA}$ ) in $5 \% \mathrm{CO}_{2}$ at $37^{\circ} \mathrm{C}$.

Grouping and transfection. In order to explore the role of miR-378 and the efficiency of the combined method for cell transfection, the cells were grouped as Blank, miR-378 control, L group (HCC cells transfected with miR-378) and LUS groups (HCC cells treated with miR-378 mimic combined with ultrasonic irradiation and SonoVue microbubbles). Briefly, HuH-7, Hep3B and SK-Hep1 cells at $1 \times 10^{6}$ cells $/ \mathrm{ml}$ in the LUS or miR-378 control groups were plated in a 96-well plate and then respectively transfected with $100 \mathrm{nmol} / \mathrm{l} \mathrm{miR}-378$ mimic (Shanghai GenePharma Co., Ltd.), or miR-378 mimic control vector (Shanghai GenePharma Co., Ltd.) in a mixture with Lipofectamine $^{\circledR} 3000$ (L3000015; Thermo Fisher Scientific, Inc.) and $2.5 \mu \mathrm{g} / \mu 1$ SonoVue microbubbles (Bracco Suisse SA) under the irradiation of ultrasonic transfer apparatus via ultrasound couplant (Anhui Deepblue Medical Technology Co., Ltd.) at the parameters of $0.5 \mathrm{~W} / \mathrm{cm}^{2}$ for $30 \mathrm{sec}$. The cells in the $\mathrm{L}$ group were transfected with miR-378 mimic using Lipofectamine 3000 only, while those in the Blank group were treated with medium only. All the cells were cultured for another $72 \mathrm{~h}$ after the transfection (19). The sequence of miR-378 mimic was 5'-AGGCUCUGACUCCAGGUCC-3'; The sequence of miR-378 mimic control was 5'-UUCUCC GAACGUGUCACGUTT-3'.

Reverse transcription-quantitative ( $R T-q) P C R$. Total RNAs from HuH-7, Hep3B and SK-Hep1 cells at $1 \times 10^{6}$ cells $/ \mathrm{ml}$ were obtained using TRIzol reagent (15596018; Thermo Fisher Scientific, Inc.) and further reverse-transcribed into cDNAs following the instructions of PrimeScript RT reagent kit (Takara Biotechnology Co., Ltd.), with the conditions for reverse transcription being: $30^{\circ} \mathrm{C}$ for $60 \mathrm{~min} ; 30^{\circ} \mathrm{C}$ for $60 \mathrm{~min}$; and $95^{\circ} \mathrm{C}$ for $60 \mathrm{~min}$. The cells were then cultured for $72 \mathrm{~h}$ following the treatments for HuH-7 cells. A total of $0.5 \mu \mathrm{l}$ forward primer, $0.5 \mu 1$ reverse primer, $3 \mu \mathrm{l}$ cDNA template, $5 \mu 12$ X SYBR Green master mix (4913850001; Roche

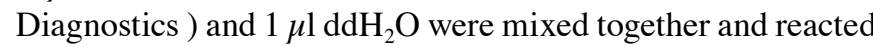
for 40 cycles in the following conditions: Initial denaturation at $95^{\circ} \mathrm{C}$ for $60 \mathrm{sec}$, at $95^{\circ} \mathrm{C}$ for $20 \mathrm{sec}$, at $65^{\circ} \mathrm{C}$ for $30 \mathrm{sec}$, and at $72^{\circ} \mathrm{C}$ for $40 \mathrm{sec}$ in Bio-Rad IQ5 thermocycler (Bio-Rad Laboratories, Inc.). The sequences of primers used are listed in Table I. Relative expression of miR-378, Cyclin D1, Bcl-2, Bax, Akt, p53 and Survivin were normalized to that of U6 by $2^{-\Delta \Delta C q}$ method (20).

Cell Counting Kit (CCK)-8. After 72 h, relative cell survival rates of HuH-7, Hep3B and SK-Hep1 cells were detected by CCK- 8 following the manufacturer's protocols (96992-100TESTS-F; Sigma-Aldrich; Merck KGaA). Briefly, $1 \times 10^{6}$ cells were collected and tested after the transfection of miR-378 mimic. Optic density (OD) values were read on a microplate reader (Multiskan; Thermo Fisher Scientific, Inc.) at $450 \mathrm{~nm}$ and relative cell survival rates of cells were calculated according to the standard curve of OD. The experiment was conducted in triplicate.

Double cytochemical staining. Cells $\left(\sim 4 \times 10^{3}-1 \times 10^{6}\right)$ were cultured in 96-well plates. EdU solution (A10044; Thermo Fisher Scientific, Inc.) was diluted by culture medium at 1,000:1 and $100 \mu \mathrm{l}$ of $50 \mu \mathrm{m}$ EdU medium was added to each well and maintained for $2 \mathrm{~h}$. The cells were washed once or twice using PBS for $5 \mathrm{~min}$. Then, $100 \mu \mathrm{l}$ cell fixative (PBS containing $4 \%$ paraformaldehyde) was added to each well and maintained for $30 \mathrm{~min}$ at room temperature. A total of $2 \mathrm{mg} / \mathrm{ml}$ glycine was added to each well for decolorization and then further incubated for $5 \mathrm{~min}$ on a shaker. PBS $(100 \mu \mathrm{l})$ was added to each well for, held for 5 min and then $100 \mu$ of penetrant $(0.5 \%$ Triton X-100 in PBS) was added to each well for $10 \mathrm{~min}$. After rinsing in PBS, 1X Hoechst 33342 reaction solution (H3570; Thermo Fisher Scientific, Inc.) was diluted by deionized water at 100:1 and added to each well for a $30 \mathrm{~min}$ incubation at room temperature in the dark. The staining result was immediately observed by using a fluorescence microscope (BX53T, Olympus Corporation; magnification, x100) after washing the cells with PBS one to three times.

Evaluation of apoptosis. Briefly, $5 \times 10^{5}$ cells were resuspended in $1 \mathrm{ml}$ cold PBS and collected into $100 \mathrm{ml}$ binding buffer using an Annexin V-FITC kit (Sigma-Aldrich; Merck $\mathrm{KGaA}$ ). A total of $10 \mu \mathrm{l}$ FITC-labeled Annexin V and $5 \mu \mathrm{l}$ propidium iodide were added to the cells for $20 \mathrm{~min}$ at room temperature. Cell apoptosis was detected using flow cytometry (BD FACSVerse Z200; FCAP Array software v3.0, Becton, Dickinson and Company) after the cells were mixed with $200 \mu$ l binding buffer and washed.

Determination of cell cycle. Followed by the detection of apoptosis rate, $1 \times 10^{6}$ cells were gathered and digested by $0.25 \%$ trypsin to determine the cell cycle in each phase. After cell transfection, Vybrant ${ }^{\mathrm{TM}}$ DyeCycle $^{\mathrm{TM}}$ Violet Stain (Thermo Fisher Scientific, Inc.) was used for flow cytometry (BD FACSVerse Z200; FCAP Array software v3.0, Becton, Dickinson and Company) to determine the phases in the cell cycle after incubation at $4^{\circ} \mathrm{C}$ for $72 \mathrm{~h}$.

Western blotting. Protein expression of Cyclin D1, Bcl-2, Bax, Akt, p53 and Survivin were detected $72 \mathrm{~h}$ later. Cells $\left(1 \times 10^{6}\right)$ were obtained and lysed in order to extract total proteins using a mixture of RIPA lysate (R0278; Sigma-Aldrich; Merck KGaA) with protease inhibitor (S8830; Sigma-Aldrich; Merck KGaA). The total proteins (50 $\mu \mathrm{g}$ per lane) from each 
Table I. Primers used in the study.

\begin{tabular}{ll}
\hline Primer name & \multicolumn{1}{c}{ Sequence (5'-3') } \\
\hline miR-378 & F: CCTGACTCCAGGTCCT \\
& R: GAACATGTCTGCGTATCTC \\
Cyclin D1 & F: GTCTTCCCGCTGGCCATGAACTAC \\
& R: GGAAGCGTGTGAGGCGGTAGTAGG \\
Bcl-2 & F: GCCTTCTTTGAGTTCGGTG \\
& R: CAGAGACAGCCAGGAGAAATC \\
Bax & F: GCAAACTGGTGCTCAAGG \\
& R: CGCCACAAAGATGGTCAC \\
Akt & F: TGGACTACCTGCACTCGGAGAA \\
& R: GTGCCGCAAAAGGTCTTCATGG \\
p53 & F: TAAAAGATGTTTGAATG \\
Survivin & R: ATGTGTGTGATGTTGTAGATG \\
& F: CCACTGAGAACGAGCCAGACTT \\
U6 & R: GTATTACAGGCGTAAGCCACCG \\
& F: GCTTCGGCAGCACATATACTAAAAT \\
& R: GAAGATGGTGATGGGATTC
\end{tabular}

miR, microRNA.

sample was separated on $10 \%$ SDS-PAGE at $120 \mathrm{~V}$ for $\sim 1.5$ h. ReBlot Plus kit (2500; Sigma-Aldrich; Merck KGaA) was used to strip antibodies. In brief, $1 \mathrm{X}$ Antibody Solution was added to the protein suspension and incubated at room temperature for $15 \mathrm{~min}$, and then transferred to a PVDF membrane, which was then blocked by $5 \%$ milk (non-fat) at room temperature for $1 \mathrm{~h}$. Next, primary antibodies against Cyclin D1 (cat. no. ab16663), Bcl-2 (cat. no. ab59348), Bax (cat. no. ab32503), Akt (cat. no. ab8805), p53 (cat. no. ab26), Survivin (cat. no. ab469), $\beta$-catenin (cat. no. ab32572) and GAPDH (cat. no. ab8245; all purchased from Abcam) were diluted to $1: 1,000$ by $5 \%$ milk (non-fat) and used to incubate with the PVDF membrane at $4^{\circ} \mathrm{C}$ overnight. The membrane was then probed with a goat anti-rabbit horseradish peroxidase conjugated-secondary antibody (1:2,000; cat. no. ab6721; Abcam) at room temperature for 1 and washed by PBST (PBS with $0.1 \%$ Tween). A SignalFire ${ }^{\mathrm{TM}}$ ECL reagent (cat. no. 6883; Cell Signaling Technology , Inc.) was used for the detection of proteins. Image $\mathrm{Lab}^{\mathrm{TM}}$ Software (version 3.0) was used for densitometric analysis and quantification of the western blot data (Bio-Rad Laboratories Inc.).

Statistics. Results from the present study were analyzed by GraphPad Prism v8.0 (GraphPad Software, Inc.). The mean value in each group was compared by one-way ANOVA. Tukey's test was used as a post-hoc test following ANOVA. $\mathrm{P}<0.05$ was considered to indicate a statistically significant difference.

\section{Results}

miR-378 inhibits the proliferation of $\mathrm{HuH}-7$ cells more efficiently using a combination of ultrasonic irradiation and SonoVue microbubbles method. To investigate the role of miR-378 on the proliferation of HuH-7, Hep3B and SK-Hep1 cells, and the efficiency of transfection using ultrasonic irradiation in combination with SonoVue microbubbles, cell survival rate was detected by performing CCK-8 and cell proliferation rate was measured using double cytochemical staining. In the present study, the results revealed that the relative expression of miR-378 in the L group was significantly increased compared with that in the Blank group $(\mathrm{P}<0.01)$, and in the LUS group this expression was significantly increased compared with that in the miR-378 control and $\mathrm{L}$ groups $(\mathrm{P}<0.001$; Fig. 1A-C). Moreover, the relative cell survival rate (\%) of $\mathrm{HuH}-7, \mathrm{Hep} 3 \mathrm{~B}$ and SK-Hep1 cells in the L group was reduced compared with that in the Blank group, and was also reduced in the LUS group compared with that in the miR-378 control and L groups $(\mathrm{P}<0.05$ and $\mathrm{P}<0.01$, respectively; Fig. 1D-F). Furthermore, the cell proliferation rate (\%) of Huh-7 cells in the L and LUS groups demonstrated a similar trend to that of the cell survival rate $(\mathrm{P}<0.05$ and $\mathrm{P}<0.01$, respectively; Fig. $1 \mathrm{G}$ and $\mathrm{H}$ ). Thus, these data suggested that miR-378 expression contributed to the suppression of the proliferation of HuH-7 cells and that the combination of ultrasonic irradiation and SonoVue microbubbles method was more effective in the transfection of miRNA.

miR-378 increases the apoptosis rate and arrests the cell cycle of HuH-7 cells more efficiently using a combined method of ultrasonic irradiation and SonoVue microbubbles. Cell apoptosis and cell cycle of each phase were then evaluated. As expected, the apoptosis rate (\%) of $\mathrm{HuH}-7$ cells in the L group was increased compared with that in the Blank group, moreover, it was significantly elevated in the LUS group compared with that in the miR-378 control and L groups $(\mathrm{P}<0.001$; Fig. 2A and B). Furthermore, the percentage of $\mathrm{HuH}-7$ cells in the $\mathrm{G} 1$ phase in the $\mathrm{L}$ group was increased compared with that in the Blank group, but it was much higher in the LUS group than that in the miR-378 control and $\mathrm{L}$ groups $(\mathrm{P}<0.05$ and $\mathrm{P}<0.01$, respectively; Fig. $2 \mathrm{C}$ and $\mathrm{D})$. However, the $\mathrm{S}$ and $\mathrm{G} 2$ phase in the L group were significantly lower than that in the miR-378 control group, while the two phases in the LUS group were reduced compared with those in the miR-378 control and L groups, and no significant difference between the L and LUS groups on $\mathrm{S}$ phase was observed $(\mathrm{P}<0.05, \mathrm{P}<0.01$ and $\mathrm{P}<0.001$; Fig. 2C and D). Thus, miR-378 expression could increase the rate of apoptosis and arrest the cell cycle of $\mathrm{HuH}-7$ cells in G1 phase more efficiently using a combination of ultrasonic irradiation and SonoVue microbubbles method. Similarly, the apoptosis rate (\%) of Hep3B cells in the L group was increased compared with that in the Blank group and it was significantly higher in the LUS group compared with that in the miR-378 control and $\mathrm{L}$ groups $(\mathrm{P}<0.001$; Fig. $2 \mathrm{E}$ and $\mathrm{F})$. Moreover, the apoptosis rate (\%) of SK-Hep1 cells in the $\mathrm{L}$ group was higher than that in the Blank group and it was significantly increased in the LUS group compared with that in the miR-378 control and $\mathrm{L}$ groups $(\mathrm{P}<0.001$; Fig. $2 \mathrm{G}$ and $\mathrm{H})$.

miR-378 regulates genes related to apoptosis and proliferation of $\mathrm{HuH}-7$ cells. The present study also explored whether genes related to apoptosis and the proliferation of HuH-7 cells could be affected by miR-378 expression, and the efficiency of the 

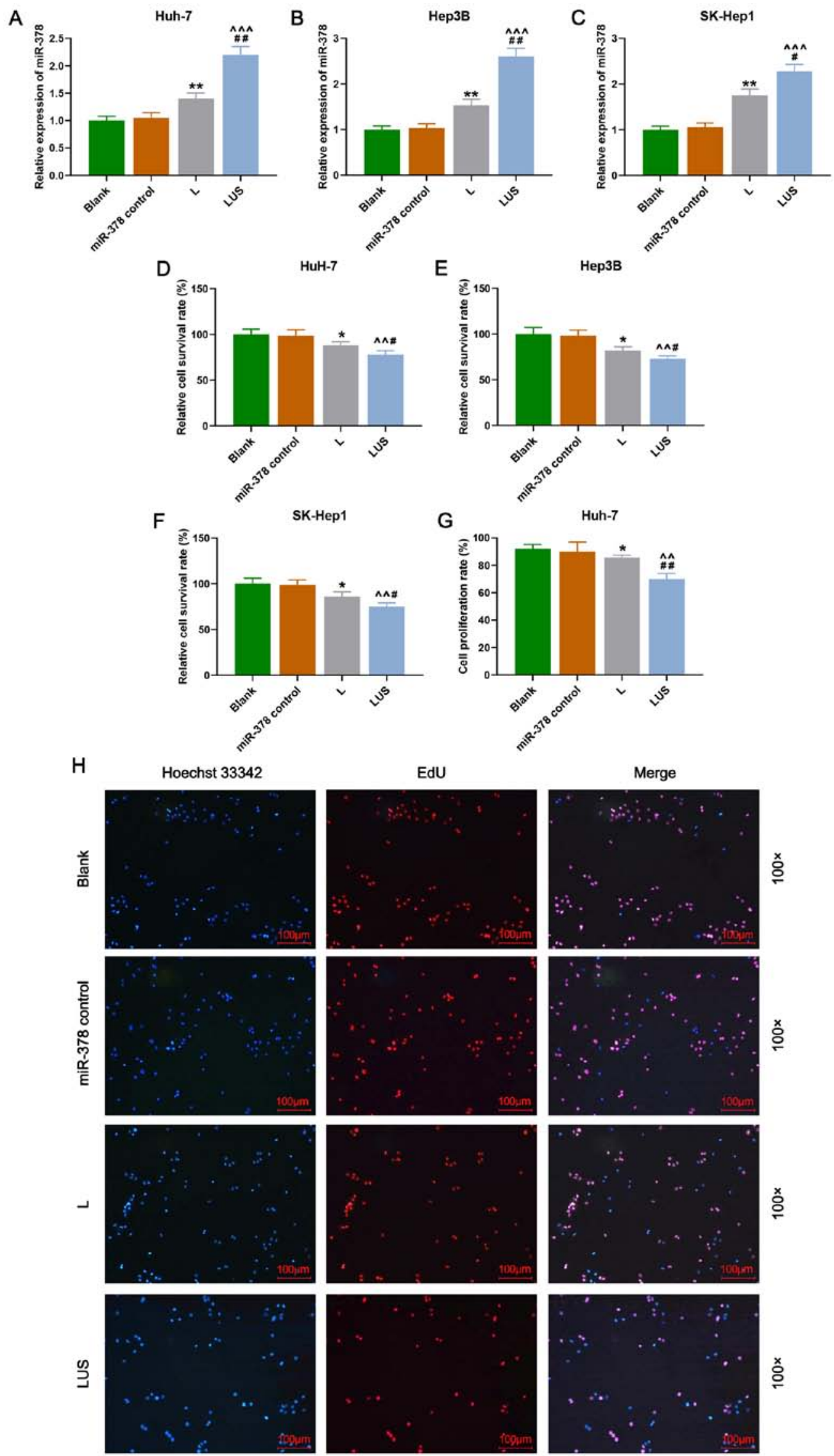

Figure 1. miR-378 inhibits the proliferation of HuH-7 cells much more efficiently using a combination of ultrasonic irradiation and the SonoVue microbubbles method. Relative expression of miR-378 in (A) Huh-7, (B) Hep3B and (C) SK-Hep-1 cells. Cell survival rate (\%) was detected by Cell Counting Kit-8 in (D) HuH-7, (E) Hep3B and (F) SK-Hep1 cells. (G) Cell proliferation rate (\%) of Huh-7 cells in Blank, miR-378 control, L and LUS groups. (H) Double cytochemical staining of Hoechst 33342 (blue) and EdU (red) in each group. Bars indicate mean $\pm \mathrm{SD}$. ${ }^{*} \mathrm{P}<0.05$ and ${ }^{* *} \mathrm{P}<0.01$, vs. Blank; ${ }^{\wedge \wedge} \mathrm{P}<.0 .1$ and ${ }^{\wedge \wedge} \mathrm{P}<0.001$ vs. miR-378 control; ${ }^{~} \mathrm{P}<0.05$ and ${ }^{\# \#} \mathrm{P}<0.01$ vs. $\mathrm{L}$. $\mathrm{L}$ group, the hepatocellular carcinoma cells were transfected with miR-378; LUS group, the hepatocellular carcinoma cells were treated with miR-378 mimic combined with Ultrasonic irradiation and SonoVue microbubbles. miR, microRNA. 
A

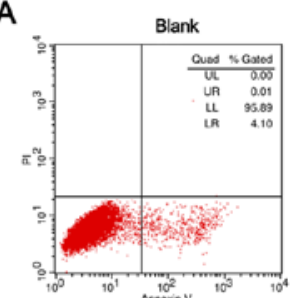

B

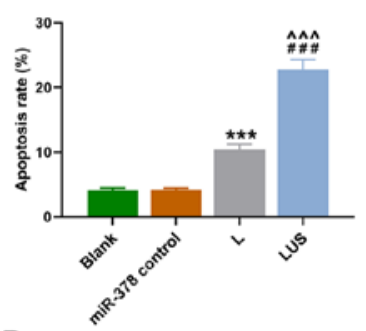

D
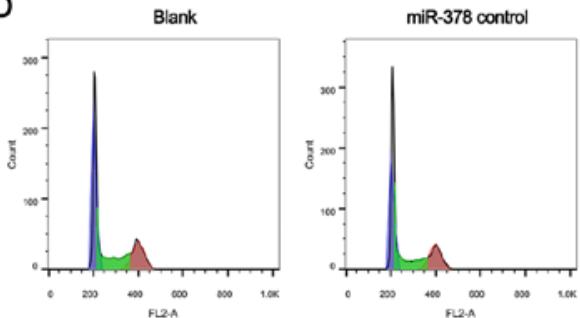

C
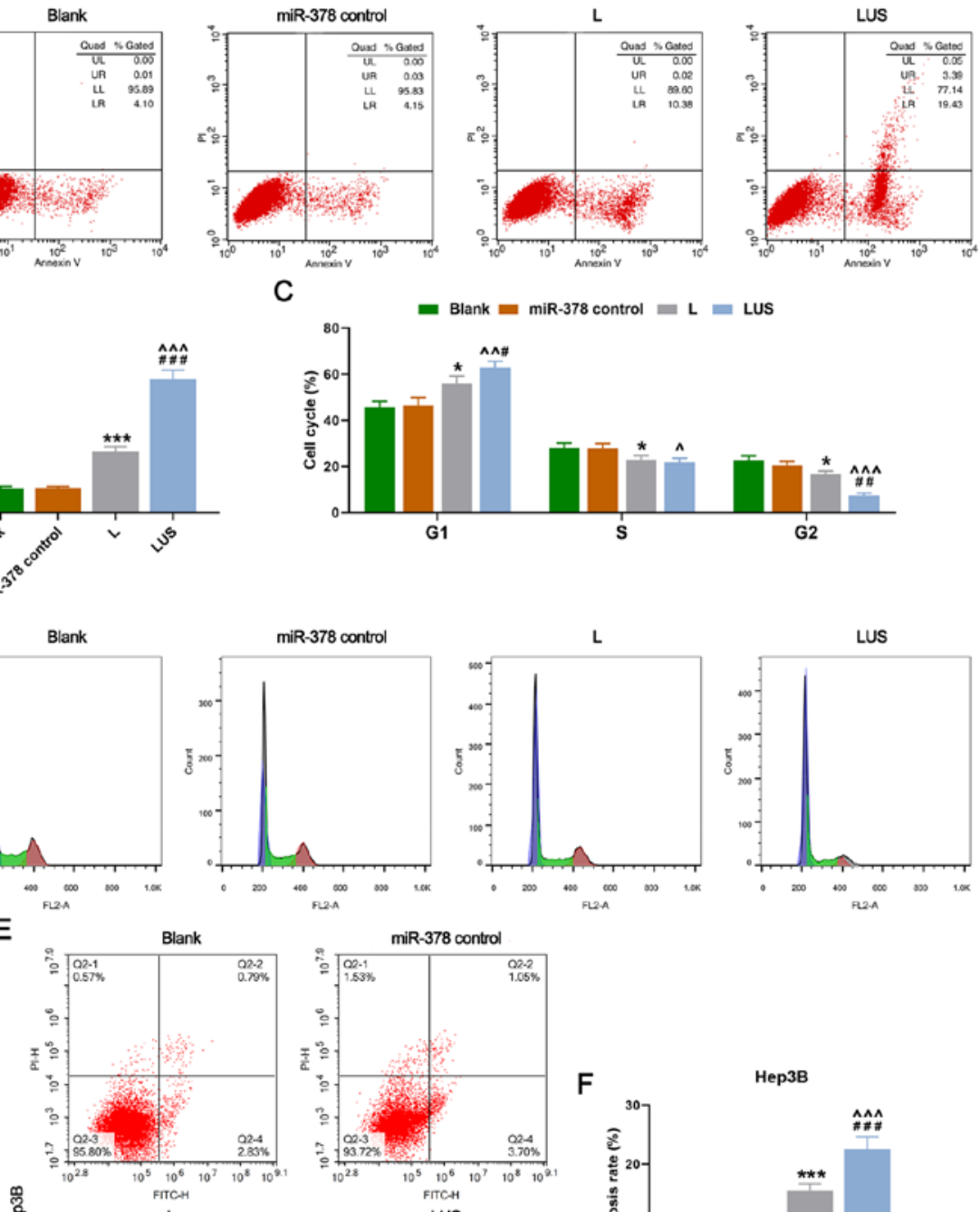

US
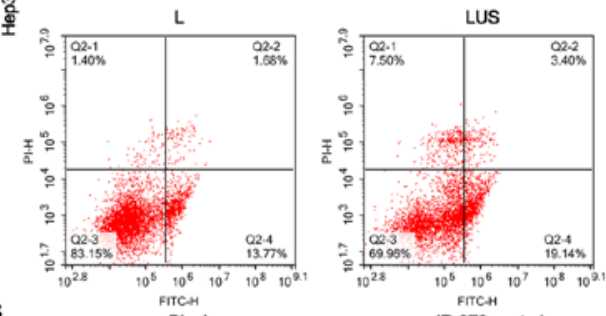

F

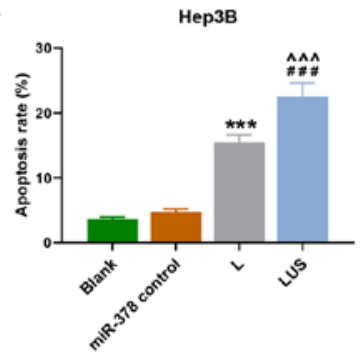

G

Blank
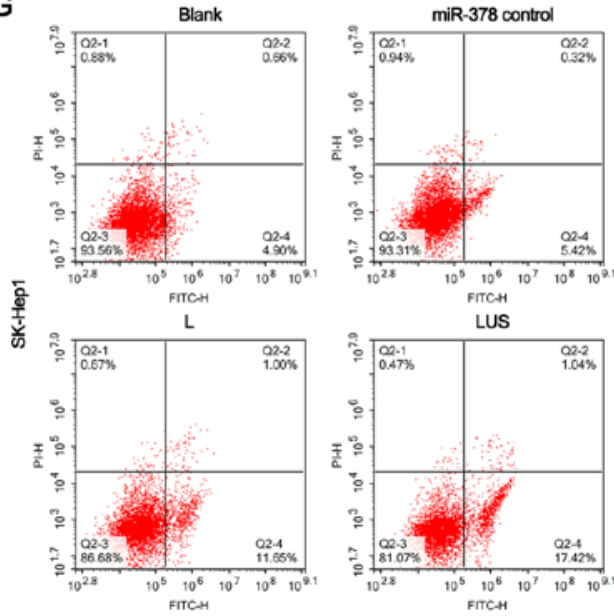

$\mathrm{H}$

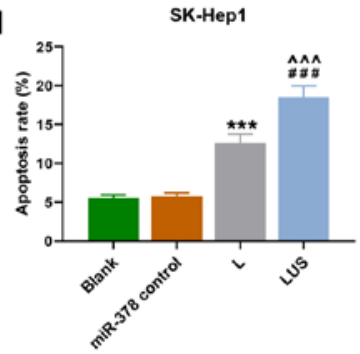

Figure 2. miR-378 increases the rate of apoptosis and arrests the cell cycle of HuH-7 cells more efficiently using the combined method. (A) Rate of apoptosis of HuH-7 cells in Blank, miR-378 control, L and LUS groups detected by detection flow cytometry. (B) Apoptosis rate (\%) in each group. (C) Cell cycle (\%) of each phase in each group. (D) Cell cycle assessment using flow cytometry in each group. Flow cytometry was used to detect cell apoptosis in (E and F) Hep3B and $(\mathrm{G}$ and $\mathrm{H})$ SK-Hep1 cells. Bars indicate mean $\pm \mathrm{SD}$. ${ }^{*} \mathrm{P}<0.05$ and ${ }^{* * * *} \mathrm{P}<0.001$ vs. Blank; ${ }^{\wedge} \mathrm{P}<0.05,{ }^{\wedge} \mathrm{P}<0.01$ and ${ }^{\wedge \wedge} \mathrm{P}<0.001 \mathrm{vs}$. $\mathrm{miR}-378 \mathrm{control} ;{ }^{\#} \mathrm{P}<0.05$, ${ }^{\# \#} \mathrm{P}<0.01$ and ${ }^{\# \# \#} \mathrm{P}<0.001$ vs. L. L group, the hepatocellular carcinoma cells were transfected with miR-378; LUS group, the hepatocellular carcinoma cells were treated with miR-378 mimic combined with Ultrasonic irradiation and SonoVue microbubbles. miR, microRNA. 

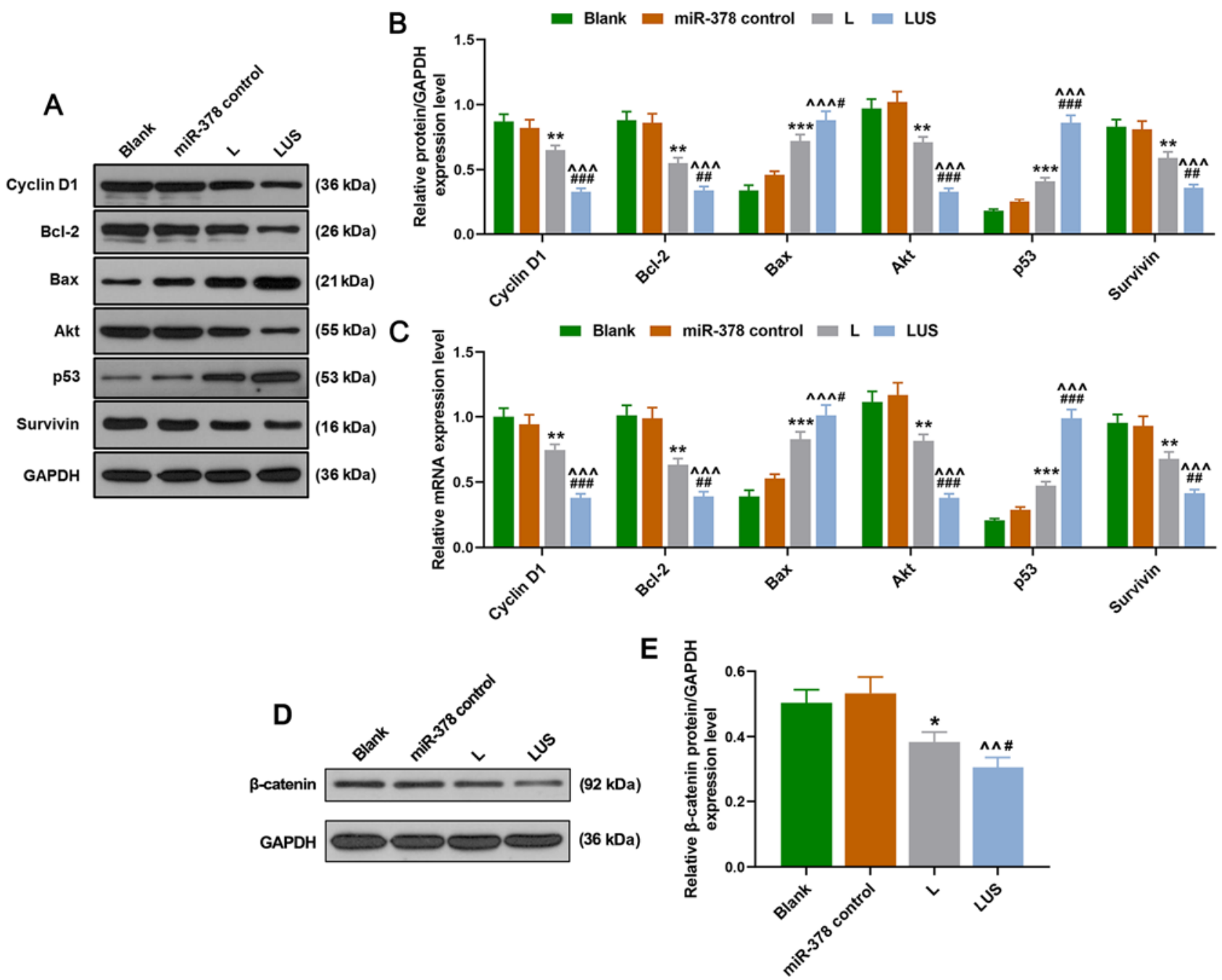

Figure 3. miR-378 regulates genes related to apoptosis and proliferation of HuH-7 cells more efficiently. (A) Western blot images showing protein expression of Cyclin D1, Bcl-2, Bax, Akt, p53 and Survivin in Blank, miR-378 control, L and LUS groups. Histograms showing (B) relative protein and (C) mRNA expression levels in each group. (D) Western blotting was used to measure the expression of $\beta$-catenin. (E) Relative expression of $\beta$-catenin was quantified via western blotting. Bars indicate mean $\pm \mathrm{SD}$. ${ }^{*} \mathrm{P}<0.05,{ }^{* * *} \mathrm{P}<0.01$ and ${ }^{* * * *} \mathrm{P}<0.001 \mathrm{vs}$. Blank; ${ }^{\wedge} \mathrm{P}<0.01$ and ${ }^{\wedge \wedge} \mathrm{P}<0.001$ vs. miR -378 control; ${ }^{\#} \mathrm{P}<0.05,{ }^{\# \#} \mathrm{P}<0.01$ and

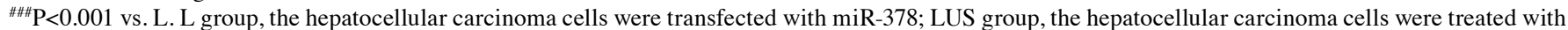
miR-378 mimic combined with Ultrasonic irradiation and SonoVue microbubbles. miR, microRNA.

combined transfection method. In the current study, the data revealed that the protein and mRNA expression levels of Cyclin D1, Bcl-2, Akt and Survivin in the L group were lower than those in the miR-378 control group, and the levels were significantly decreased in the LUS group compared with those in the $\mathrm{L}$ and miR-378 control groups $(\mathrm{P}<0.01$ and $\mathrm{P}<0.001$; Fig. 3A-C). On the other hand, the expression of Bax and p53 exhibited a different trend, expression increased in the $\mathrm{L}$ and LUS groups compared with the miR-378 control and Blank groups, with the highest expression found in the LUS group $(\mathrm{P}<0.05$ and $\mathrm{P}<0.001 ;$ Fig. $3 \mathrm{~A}-\mathrm{C})$. In addition, $\beta$-catenin expression was significantly reduced in the LUS group compared with that in the miR-378 control and $\mathrm{L}$ groups $(\mathrm{P}<0.05$ and $\mathrm{P}<0.001$; Fig. 3D-E). Taken together, these results indicated that miR-378 expression led to a decrease in the expression of proliferation-related genes and increased the expression of apoptosis-related genes. Additionally, it was demonstrated that the use of combined ultrasonic irradiation and SonoVue microbubbles method for the transfection of miR-378 was more effective.

\section{Discussion}

At present, miRNAs have been increasingly found to have important roles in the development of cancer. It has been shown that miR-146a not only has a tumor-suppressive effect, but also plays a critical role in the growth of HCC cells and that genetic variation of miR-146a may be a risk factor for developing HCC (21). The expression of miR143HG was significantly downregulated in HCC cells and tissues, and was associated with the staging and prognosis of patients with HCC (22). Furthermore, previous research has also suggested that the upregulation of miR-21-5p may be a functional regulator of HCC apoptosis and could be a new tumor marker for early diagnosis of HCC (23). The current study examined the effects of miR-378 overexpression on HuH-7 cells and explored the efficiency of the combined transfection method of ultrasonic irradiation and SonoVue microbubbles. The results demonstrated that miR-378 functioned as a suppressor in the proliferation of HuH-7, Hep3B and SK-Hep1 cells, and this effect of miR-378 could be enhanced by using the combined 
method. Thus, these results indicated that a combined transfection approach is useful and may have potential in gene therapy.

Overexpressed miR-378 could be transfected into HuH-7, Hep3B and SK-Hep1 cells, which are representative of hepatoma cells. Furthermore, it was found that miR-378 overexpression reduced the proliferation ability and increased the apoptosis rate of HuH-7, Hep3B and SK-Hep1 cells. The cell cycle is a process during which cells undergo a series of controls and regulations to maintain an orderly progression of cell growth and proliferation (24-26). Cyclin/CDK is a promoter of the cell cycle (24-26). Cyclin D1, a member of the Cyclin family and also a proto-oncogene, promotes cell G1/S phase via CDK, thereby promoting cancer development (24-26). p53 is a tumor suppressor gene located at $17 \mathrm{p}$ in human chromosomes and is normally expressed at low levels in the nucleus (27-30). Mutated p53 genes have been found in various human tumors, including in HCC (27-30). p53 proteins are involved in several cellular processes, including gene transcription, DNA repair, cell cycle, genome stabilization, chromosome segregation, senescence, apoptosis and angiogenesis (27-30). The p53 signal transduction pathway is an important signaling pathway regulating G1/S phase (27-30). The role of the Bcl-2 family in apoptosis has received much attention (31), Bcl-2 is an inhibitor of apoptosis protein, while Bax is an apoptosis-promoting protein, these two factors are closely related to the regulation of apoptosis (31-34). Specifically, Bax forms a heterodimer with Bcl-2, thereby inhibiting the function of Bcl-2 (35-37), moreover, the susceptibility of cell apoptosis depends on the ratio of Bax/Bcl-2, which also determines cell survival after receiving apoptosis signals, thus, the ratio plays an important role in tumor occurrence (35-37). Akt is a serine/threonine protein kinase (38-40) and when cells are stimulated by growth factors, PI3K activates and produces PIP3 that binds to the $\mathrm{PH}$ domain of Akt to trigger the recruitment of Akt to the cell membrane (38-40). This process is involved in resistance to apoptosis, glucose metabolism, protein synthesis and could promote cell growth and proliferation (38-40). Survivin is one of the members of the IAP family with the lightest molecular weight $(41,42)$ and it specifically binds to mitotic spindles during G2/M phase and can inhibit caspase-3, caspase-7, caspase- 8 and cytochrome $\mathrm{C}$, which are the key factors in apoptosis signaling pathways, therefore it can promote cancer development $(41,42)$. In the present study, expression of Cyclin D1, Bcl-2, Akt and Survivin were reduced in HuH-7 cells transfected with miR-378, while Bax and p53 expression was elevated, suggesting that the proliferation of $\mathrm{HuH}-7$ cells was downregulated and apoptosis was increased by the overexpression of miR-378.

Several researchers have investigated the role of miR-378 in hepatoma. An et al (43) reported that in a Chinese population, mutant miR-378 was related to the prognosis of HCC. Similarly, Hyun et al (44) revealed that the activation of hepatic stellate cells and the liver fibrosis process could be suppressed by miR-378. In addition, Zhou et al (45) found that miR-378 could be overexpressed by metformin to reduce proliferation of HCC. Thus, miR-378 may be a suppressor in the process of hepatoma.

Interestingly, in the present study it was found that when miR-378 was transfected into HuH-7, Hep3B and SK-Hep1 cells by the combined method of ultrasonic irradiation and SonoVue microbubbles, the suppressive effect of miR-378 was more significant. Ran et al (19) indicated that interference of the target gene by short interfering RNA using the combined method of ultrasonic irradiation and SonoVue microbubbles was more efficient than using the lipidosome method for cell transfection. Li et al (46) also showed that SonoVue and ultrasound irradiation may have promising effects in breast cancer therapy by delivering the target genes effectively.

Generally, traditional viral transfection and lipofection methods limit the functionality of target genes in target cells, due to their low safety and poor transfection efficiency $(47,48)$. However, SonoVue differs from traditional gene vector microbubbles and can overcome such limitations (49). When SonoVue microbubbles are irradiated by ultrasound, they can produce continuous compression or expansion, leading to the rupture of microbubbles with accompanied cavitation effect (50). Thus, the permeability of the target tissue or cell membrane is increased, which promotes the entry of the gene into the target cells (50).

In conclusion, miR-378 is shown to be a suppressive factor in HCC, as it suppresses the proliferation and increases the apoptosis of HCC cells. Moreover, the combination of ultrasonic irradiation and SonoVue microbubbles method is more efficient in the transfection of miRNA. Therefore, the present findings contribute to the current gene therapy for hepatoma, however, the feasibility of such a method should be further explored.

\section{Acknowledgements}

Not applicable.

\section{Funding}

No funding was received.

\section{Availability of data and materials}

The datasets used and/or analyzed during the current study are available from the corresponding author on reasonable request.

\section{Authors' contributions}

JW and YL made substantial contributions to study conception and design, drafted the article and critically revised it for important intellectual content. QM and JH were involved in data acquisition, analysis and interpretation. All authors gave final approval of the version to be published and agree to be accountable for all aspects of the work in ensuring that questions related to the accuracy or integrity of the work are appropriately investigated and resolved. All authors read and approved the final manuscript.

\section{Ethics approval and consent to participate}

Not applicable.

\section{Patient consent for publication}

Not applicable. 


\section{Competing interests}

The authors declare that they have no competing interests.

\section{References}

1. Cheng AL, Kang YK, Chen Z, Tsao CJ, Qin S, Kim JS, Luo R, Feng J, Ye S, Yang TS, et al: Efficacy and safety of sorafenib in patients in the Asia-Pacific region with advanced hepatocellular carcinoma: A phase III randomised, double-blind, placebo-controlled trial. Lancet Oncol 10: 25-34, 2009.

2. Llovet JM, Ricci S, Mazzaferro V, Hilgard P, Gane E, Blanc JF, de Oliveira AC, Santoro A, Raoul JL, Forner A, et al: Sorafenib in advanced hepatocellular carcinoma. N Engl L Med 359: 378-390, 2008

3. Bruix J and Sherman M; American Association for the Study of Liver Diseases: Management of hepatocellular carcinoma: An update. Hepatology 53: 1020-1022, 2011.

4. Llovet JM and Bruix J: Systematic review of randomized trials for unresectable hepatocellular carcinoma: Chemoembolization improves survival. Hepatology 37: 429-442, 2003.

5. Nam SW, Park JY, Ramasamy A, Shevade S, Islam A, Long PM Park CK, Park SE, Kim SY, Lee SH, et al: Molecular changes from dysplastic nodule to hepatocellular carcinoma through gene expression profiling. Hepatology 42: 809-818, 2005.

6. Hoshida Y, Villanueva A, Kobayashi M, Peix J, Chiang DY, Camargo A, Gupta S, Moore J, Wrobel MJ, Lerner J, et al: Gene expression in fixed tissues and outcome in hepatocellular carcinoma. N Engl J Med 359: 1995-2004, 2008.

7. Van Roosbroeck $\mathrm{K}$ and Calin GA: Cancer hallmarks and MicroRNAs: The therapeutic connection. Adv Cancer Res 135: 119-149, 2017.

8. Wang G, Song L, Hou X, Kala S, Wong KF, Tang L, Dai Y and Sun L: Surface-modified GVs as nanosized contrast agents for molecular ultrasound imaging of tumor. Biomaterials 236 : 119803, 2020.

9. Qiu L, Leng QY and Luo Y: Progress of ultrasound microbubble contrast technology in the diagnosis and treatment of clinical diseases. Sichuan Da Xue Xue Bao Yi Xue Ban 45: 974-978, 2014 (In Chinese).

10. Liu Y, Miyoshi H and Nakamura M: Encapsulated ultrasound microbubbles: Therapeutic application in drug/gene delivery. J Control Release 114: 89-99, 2006.

11. Price RJ and Kaul S: Contrast ultrasound targeted drug and gene delivery: An update on a new therapeutic modality. J Cardiovasc Pharmacol Ther 7: 171-180, 2002.

12. Wallace $\mathrm{N}$ and Wrenn SP: Ultrasound triggered drug delivery with liposomal nested microbubbles. Ultrasonics 63: 31-38, 2015.

13. Mountford PA, Sirsi SR and Borden MA: Condensation phase diagrams for lipid-coated perfluorobutane microbubbles. Langmuir 30: 6209-6218, 2014.

14. Kooiman K, van Rooij T, Qin B, Mastik F, Vos HJ, Versluis M, Klibanov AL, de Jong N, Villanueva FS and Chen X: Focal areas of increased lipid concentration on the coating of microbubbles during short tone-burst ultrasound insonification. PLoS One 12 e0180747, 2017.

15. Myrset AH, Fjerdingstad HB, Bendiksen R, Arbo BE, Bjerke RM, Johansen JH, Kulseth MA and Skurtveit R: Design and characterization of targeted ultrasound microbubbles for diagnostic use. Ultrasound Med Biol 37: 136-150, 2011.

16. Lammertink B, Deckers R, Storm G, Moonen C and Bos C: Duration of ultrasound-mediated enhanced plasma membrane permeability. Int J Pharm 482: 92-98, 2015.

17. Yang PS, Tung FI, Chen HP, Liu TY and Lin YY: A novel bubble-forming material for preparing hydrophobic-agent-loaded bubbles with theranostic functionality. Acta Biomater 10: 3762-3774, 2014

18. Rychak JJ and Klibanov AL: Nucleic acid delivery with microbubbles and ultrasound. Adv Drug Deliv Rev 72: 82-93, 2014.

19. Ran LW, Wang H, Lan D, Jia HX and Yu SS: Effect of RNA interference targeting STAT3 gene combined with ultrasonic irradiation and SonoVue microbubbles on proliferation and apoptosis in keratinocytes of psoriatic lesions. Chin Med J (Engl) 131: 2097-2104, 2018.

20. Livak KJ and Schmittgen TD: Analysis of relative gene expression data using real-time quantitative PCR and the 2(-Delta Delta C(T)) method. Methods 25: 402-408, 2001
21. Wang H, Li X, Li T, Wang L, Wu X, Liu J, Xu Y and Wei W: Multiple roles of microRNA-146a in immune responses and hepatocellular carcinoma. Oncol Lett 18: 5033-5042, 2019.

22. Lin X, Xiaoqin H, Jiayu C, Li F, Yue L and Ximing X: Long non-coding RNA miR143HG predicts good prognosis and inhibits tumor multiplication and metastasis by suppressing mitogen-activated protein kinase and Wnt signaling pathways in hepatocellular carcinoma. Hepatol Res 49: 902-918, 2019.

23. Zhong XZ, Deng Y, Chen G and Yang H: Investigation of the clinical significance and molecular mechanism of miR-21-5p in hepatocellular carcinoma: A systematic review based on 24 studies and bioinformatics investigation. Oncol Lett 17: 230-246, 2019.

24. Kim JK and Diehl JA: Nuclear cyclin D1: An oncogenic driver in human cancer. J Cell Physiol 220: 292-296, 2009.

25. Qie S and Diehl JA: Cyclin D1, cancer progression, and opportunities in cancer treatment. J Mol Med (Berl) 94: 1313-1326, 2016

26. Witzel II, Koh LF and Perkins ND: Regulation of cyclin D1 gene expression. Biochem Soc Trans 38: 217-222, 2010.

27. Hayman L, Chaudhry WR, Revin VV, Zhelev N and Bourdon JC: What is the potential of p53 isoforms as a predictive biomarker in the treatment of cancer? Expert Rev Mol Diagn 19: 149-159, 2019.

28. Tiwari B, Jones AE and Abrams JM: Transposons, p53 and genome security. Trends Genet 34: 846-855, 2018.

29. Xue Y, San Luis B and Lane DP: Intratumour heterogeneity of p53 expression; causes and consequences. J Pathol 249: 274-285, 2019.

30. Chabeda A, Yanez RJR,Lamprecht R, Meyers AE, Rybicki EP and Hitzeroth II: Therapeutic vaccines for high-risk HPV-associated diseases. Papillomavirus Res 5: 46-58, 2018.

31. O'Neill JW and Hockenbery DM: Bcl-2-related proteins as drug targets. Curr Med Chem 10: 1553-1562, 2003.

32. Brown LM, Hanna DT, Khaw SL and Ekert PG: Dysregulation of BCL-2 family proteins by leukemia fusion genes. J Biol Chem 292: 14325-14333, 2017.

33. Peña-Blanco A and García-Sáez AJ: Bax, Bak and beyond-mitochondrial performance in apoptosis. FEBS J 285: 416-431, 2018.

34. Renault TT, Dejean LM and Manon S: A brewing understanding of the regulation of Bax function by Bcl-xL and Bcl-2. Mech Ageing Dev 161: 201-210, 2017.

35. Stefanaki C, Antoniou C, Stefanaki K, Petrikos G, Argyrakos T, Constantinidou CV, Karentzou O, Stratigos A and Katsambas A: Bcl-2 and Bax in congenital naevi. Br J Dermatol 154: 1175-1179, 2006.

36. Abu Zeid EH, Hussein MMA and Ali H: Ascorbic acid protects male rat brain from oral potassium dichromate-induced oxdative DNA damage and apoptotic changes: The expression patterns of caspase-3, P 53, Bax, and Bcl-2 genes. Environ Sci Pollut Res Int 25: 13056-13066, 2018.

37. Zhang Y, Yang X, Ge X and Zhang F: Puerarin attenuates neurological deficits via Bcl-2/Bax/cleaved caspase-3 and Sirt3/SOD2 apoptotic pathways in subarachnoid hemorrhage mice. Biomed Pharmacother 109: 726-733, 2019.

38. Lien EC, Dibble CC and Toker A: PI3K signaling in cancer: Beyond AKT. Curr Opin Cell Biol 45: 62-71, 2017.

39. Driessen GJ, IJspeert H, Wentink M, Yntema HG, van Hagen PM, van Strien A, Bucciol G, Cogulu O, Trip M, Nillesen W, et al: Increased PI3K/Akt activity and deregulated humoral immune response in human PTEN deficiency. J Allergy Clin Immunol 138: 1744-1747.e1745, 2016

40. Li Y, Fu LX, Zhu WL, Shi H, Chen LJ and Ye B: Blockade of CXCR6 reduces invasive potential of gastric cancer cells through inhibition of AKT signaling. Int J Immunopathol Pharmacol 28: 194-200, 2015.

41. Han G, Gong H, Wang Y, Guo S and Liu K: AMPK/mTOR-mediated inhibition of survivin partly contributes to metformin-induced apoptosis in human gastric cancer cell. Cancer Biol Ther 16: 77-87, 2015

42. Liu JL, Gao W, Kang QM, Zhang XJ and Yang SG: Prognostic value of survivin in patients with gastric cancer: A systematic review with meta-analysis. PLoS One 8: e71930, 2013.

43. An J, Liu J, Liu L, Liu Y, Pan Y, Huang M, Qi F, Wen J, Xie K, $\mathrm{Ma} \mathrm{H}$, et al: A genetic variant in primary miR-378 is associated with risk and prognosis of hepatocellular carcinoma in a Chinese population. PLoS One 9: e93707, 2014.

44. Hyun J, Wang S, Kim J, Rao KM, Park SY, Chung I, Ha CS, Kim SW, Yun YH and Jung Y: MicroRNA-378 limits activation of hepatic stellate cells and liver fibrosis by suppressing Gli3 expression. Nat Commun 7: 10993, 2016. 
45. Zhou J, Han S, Qian W, Gu Y, Li X and Yang K: Metformin induces miR-378 to downregulate the CDK1, leading to suppression of cell proliferation in hepatocellular carcinoma. OncoTargets Ther 11: 4451-4459, 2018.

46. Li XH, Zhou P, Wang LH, Tian SM, Qian Y, Chen LR and Zhang P: The targeted gene (KDRP-CD/TK) therapy of breast cancer mediated by SonoVue and ultrasound irradiation in vitro. Ultrasonics 52: 186-191, 2012.

47. Thomas CE, Ehrhardt A and Kay MA: Progress and problems with the use of viral vectors for gene therapy. Nat Rev Genet 4 346-358, 2003.

48. Ding B, Li T, Zhang J, Zhao L and Zhai G: Advances in liver-directed gene therapy for hepatocellular carcinoma by non-viral delivery systems. Curr Gene Ther 12: 92-102, 2012.
49. Delalande A, Bastié C, Pigeon L, Manta S, Lebertre M, Mignet N, Midoux $\mathrm{P}$ and Pichon $\mathrm{C}$ : Cationic gas-filled microbubbles for ultrasound-based nucleic acids delivery. Biosci Rep 37: BSR20160619, 2017.

50. Qin P, Han T, Yu ACH and Xu L: Mechanistic understanding the bioeffects of ultrasound-driven microbubbles to enhance macromolecule delivery. J Control Release 272: 169-181, 2018.

c) (i) Attribution-NonCommercial-NoDerivatives 4.0 International (CC BY-NC-ND 4.0) License. 